\title{
Renal tubular dysgenesis due to twin-twin transfusion
}

INSERM

\section{Source}

INSERM. (1999). Orphanet: an online rare disease and orphan drug data base. Renal tubular dysgenesis due to twin-twin transfusion. ORPHA:97367

'Renal tubular dysgenesis due to twin-twin transfusion syndrome (TTTS; see this term) is an acquired form of renal tubular dysgenesis (see this term) that develops in donor fetuses due to the uneven shunting of growth factor and nutrients to the kidney of the recipient and is characterized by absent or poorly developed proximal tubules, persistent oligohydramnios and consequently the Potter sequence (facial dysmorphism with large and flat low-set ears, lung hypoplasia, arthrogryposis and limb positioning defects).' 